\title{
Reconceptualizar a paz e a violência: Uma análise crítica
}

Reconceptualising Peace and Violence: A Critical Analysis

Re-conceptualiser la paix et la violence: une analyse critique

Maria Raquel Freire e Paula Duarte Lopes

(2) OpenEdition

\section{Journals}

Edição electrónica

URL: http://journals.openedition.org/rccs/614

DOI: $10.4000 /$ rccs. 614

ISSN: 2182-7435

\section{Editora}

Centro de Estudos Sociais da Universidade de Coimbra

\section{Edição impressa}

Data de publição: 1 Setembro 2008

Paginação: 13-26

ISSN: 0254-1106

\section{Refêrencia eletrónica}

Maria Raquel Freire e Paula Duarte Lopes, « Reconceptualizar a paz e a violência: Uma análise crítica », Revista Crítica de Ciências Sociais [Online], 82 | 2008, colocado online no dia 01 outubro 2012, criado a 19 abril 2019. URL : http://journals.openedition.org/rccs/614 ; DOI : 10.4000/rccs.614 


\section{MARIA RAQUEL FREIRE PAULA DUARTE LOPES}

\section{Reconceptualizar a paz e a violência: Uma análise crítica}

Os estudos para a paz encontram-se actualmente numa encruzilhada, sendo criticados pelo seu programa de investigação demasiado amplo, pela sua posição acrítica relativamente à terminologia utilizada e pela desconexão entre investigação e acção. Este artigo propõe a reconceptualização do núcleo teórico dos estudos para a paz, não só retomando a paz como valor central, mas também enquadrando o binómio investigação-acção numa cultura da paz. Parte-se de uma crítica à narrativa convencional sobre conflitos, a qual evoluiu com a Agenda para a Paz de Boutros Ghali, reflectindo desde então uma narrativa centrada na paz. Contudo, apesar da adopção de uma nova agenda política para a paz, os resultados práticos não têm reflectido esta alteração, que se tem revelado mais formal do que operacional. O artigo defende, assim, que a paz e a violência não são mutuamente exclusivas, adoptando o conceito do continuum de pazes e violências e propondo uma peace web para melhor enquadrar as dinâmicas em questão, atendendo especialmente ao âmbito da implementação.

\section{Introdução}

Num cenário de pós-pós-guerra fria, a perspectiva dos estudos para a paz sobre o sistema internacional deve reflectir o carácter multidimensional da paz e da violência, bem como o facto de os dois conceitos não serem mutuamente excludentes. Deve reflectir ainda a dinâmica das diferentes escalas (individual, comunitária, societal e internacional), onde o continuum de pazes e violências decorre. As exigências de uma ordem pós-vestefaliana, em contraste com um sistema internacional ainda muito estato-cêntrico, contribuem para este processo, em que se torna visível a natureza evolutiva das abordagens da violência e da paz.

Desde a sua criação que os estudos para a paz têm defendido uma mudança de paradigma, ainda não concretizada. Esta mudança requer uma abordagem distinta relativamente à terminologia utilizada, e aos meios, recursos humanos e instrumentos. Implica ainda a transformação da narrativa linear do conflito numa peace web, onde diferentes áreas de intervenção se encontram interligadas e centradas na paz. 
O presente artigo começa por apresentar uma revisão da bibliografia sobre os estudos para a paz, como enquadramento para a nossa proposta conceptual. A secção conceptual discute os conceitos de paz, culturas das pazes e o continuum de pazes e violências, discutindo a crítica à abordagem tradicional da narrativa do conflito que subjaz aos estudos para a paz e à sua operacionalização. Nesta crítica, recorremos à análise das missões de manutenção da paz das Nações Unidas (NU) como um exemplo ilustrativo da desconexão existente entre investigação e acção nos estudos para a paz. $\mathrm{O}$ artigo apresenta e desenvolve, em seguida, a proposta conceptual baseada na peace web, a qual é enraízada no conceito de culturas das pazes. A peace web identifica quatro áreas de intervenção correlacionadas - promoção da paz, peacemaking, peacekeeping e peacebuilding - as quais não são sequenciais, sendo abordadas com diferentes níveis de intensidade. Estas áreas distintas de intervenção encontram-se estruturadas em culturas de pazes e, combinadas, resultam numa estratégia sustentável para a paz, que por sua vez implica um retorno ao valor central da paz. A conclusão identifica linhas de análise para investigação futura.

\section{Estudos para a paz: ontem e hoje}

Os estudos para a paz distanciam-se do paradigma estato-cêntrico realista em relações internacionais, definindo-se como uma abordagem 'rejeccionista' (Dunn, 2005: 37). Rejeitam as premissas dos estudos de segurança e estratégicos, em que conflito e guerra são uma constante que tem de ser gerida e mitigada. Os estudos para a paz rejeitam também o pressuposto de que a violência é "uma condição essencialmente inescapável associada ao ser humano" (Dunn, 2005: 40). Na realidade, para os estudos estratégicos, a "paz tem merecido pouca importância" (Terriff et al., 1999: 65), o que implicou que, após a Segunda Guerra Mundial, os estudos para a paz fossem "entendidos essencialmente como um movimento de protesto intelectual” (ibid.: 65).

Os estudos para a paz pressupõem que, embora os seres humanos tenham capacidade para infligir dor, também têm capacidade para cooperar e para escolherem um caminho não-violento perante situações de conflito. Ignorar esta dualidade e a possibilidade de escolha, é destinar a humanidade a uma vida "solitária, pobre, sórdida, selvagem, e curta" (Hobbes, 1651: cap. xxviii), é "distorcer as capacidades dos seres humanos, é um idealismo mal intencionado" (Martinez Guzmán, 2005: 45-46).

Apesar desta abordagem 'rejeccionista', os primeiros investigadores para a paz, como Johan Galtung no Reino Unido e Kenneth Boulding e Anatol Rappaport nos Estados Unidos da América, não aderiram a uma simples 
rejeição da interpretação dos principais pressupostos do paradigma realista dominante. Inspirados na tradição kantiana, estavam interessados na 'paz' propriamente dita, não com o objectivo de "gerir o status quo a favor de uns ou outros, mas no sentido de o mudar" (Terriff et al., 1999: 70). As contribuições principais de Boulding e Rappaport "ajudaram a definir áreas específicas de interesse e uma metodologia para os estudos para a paz" (Mason, 2002: 17), tais como o 'dilema do prisioneiro', 'paz estável' e 'culturas de paz' (Boulding, 2000).

Johan Galtung também contribuiu de forma fundamental ao definir paz como mais do que a ausência de guerra (violência directa), interpretando paz num sentido positivo ao incluir violências estruturais e culturais (Galtung, 1969). A violência directa refere-se à violência física e psicológica exercida directamente sobre uma pessoa. Quanto à violência estrutural, é uma forma de violência indirecta que resulta da "própria estrutura social - entre humanos, entre grupos de humanos (sociedades), entre grupos de sociedades (alianças, regiões) no mundo" (Galtung, 1996: 2). Por seu turno, a violência cultural traduz-se numa rede que legitima os outros dois tipos de violência através do seu sistema de normas e comportamentos (Galtung, 1996: 2). Cada uma destas violências constitui um vértice no triângulo de violências de Galtung. Este autor defende que os estudos para a paz como área de estudo não desenvolvem e aplicam simplesmente (nem deverão fazê-lo) as chamadas teorias neutras, que, posteriormente, são verificadas através de informação recolhida. Para o 'pai dos estudos para a paz', os valores constituem uma parte intrínseca da investigação que esta abordagem apresenta, com a paz como o seu 'valor central' (Galtung, 1996: 13). Este ponto de partida é essencial não só para o tipo de conclusões obtidas, mas também, e mais importante, para o tipo de acção recomendada. Note-se que os estudos para a paz têm sido definidos como uma abordagem essencialmente dirigida à acção, como uma abordagem 'investigação-acção'.

A trilogia das violências de Galtung torna visível a dinâmica global de exploração. E é a partir desta conclusão que alguns autores, como Ekkehart Krippendorff, Lars Dencik e Gunder Frank, identificam o "capitalismo como a causa principal da guerra e do conflito violento" (Terriff et al., 1999: 71). Esta tendência levou a uma radicalização dos estudos para a paz, apelando à "denúncia das dinâmicas globais de exploração e, se necessário, à sua resolução pela revolução, uma estratégia que era um anátema do ponto de vista do processo de transformação racional proposto por Galtung" (ibid:: 71). Os estudos para a paz tradicionais foram acusados de aceitarem o paradigma dominante, em que o desenvolvimento ocidental era $o$ modelo 
a ser adoptado se se tivesse como objectivo o progresso, implicando "pouco mais do que um ajustamento mínimo do equilíbrio de poderes subjacente ao status quo" (ibid.: 71). Consequentemente, os estudos para a paz transferiram o seu foco de uma "relação estratégica das superpotências", no fundo ainda abordando essencialmente a violência directa, "para as dinâmicas da relação Norte-Sul”, alargando o objecto de investigação para incluir a violência estrutural global (ibid.: 71). Isto foi, no entanto, seguido por um alargamento mais lato do objecto de análise dos estudos para a paz. Rapidamente, todo e qualquer problema social era passível de ser ligado a dinâmicas de paz e violência e, desse modo, poderia ser analisado no quadro dos estudos para a paz (Tromp, 1981). No alinhamento de Håkan Wiberg, os estudos para a paz transformaram-se num 'buraco negro' que incluía todas as dinâmicas sociais (2005: 25). Ainda assim, este movimento de alargamento permitiu uma melhor contextualização e definição do conceito de paz, analisado nos planos individual, comunitário, societal, regional e internacional, consolidando finalmente uma perspectiva de investigação que vai além das relações estato-cêntricas de paz e violência.

Com o final da guerra fria, este 'buraco negro' começou a ganhar consistência, especialmente após as 'novas guerras' de Kaldor começarem a ser discutidas. Mary Kaldor (1999) defende que a maior parte das guerras da década de 1990 difere das guerras tradicionais internacionais. A diferença mais visível é a erosão do monopólio legítimo do uso da força por parte do Estado, uma vez que um número crescente destas 'novas guerras' é intra-estatal; os grupos beligerantes nem sempre usam uniforme nem reflectem uma organização de tipo militar; este tipo de violência é financiado internacionalmente (e ilegalmente) com apoios a uma escala nunca antes registada, tendo ligações com redes de fluxos de armas, drogas e seres humanos; e um número crescente de vítimas é civil (Kaldor, 1999). Ken Booth vai mais além ao afirmar que não se trata apenas de uma questão de "ou velhas ou novas [guerras], mas antes de um reconhecimento complexo de ambas, velhas e novas" (2001: 165). Tatiana Moura (2005) adiciona uma nova dimensão à proposta de Kaldor, baseada no continuum de violências, ao salientar dinâmicas de violência do tipo de guerra em contextos de paz formal.

$\mathrm{Na}$ primeira década do século XXI, a maior parte dos investigadores para a paz concordam que os estudos para a paz necessitam de proceder a uma reconceptualização fundamental da sua raison d'être (Pureza e Cravo, 2005). Esta preocupação deriva da constatação da existência de uma agenda demasiado ampla (Mason, 2002; Rogers e Ramsbotham, 1999), a qual acabou por incluir questões de desenvolvimento (Duffield, 2001), segu- 
rança (Buzan et al., 1997) e estudos feministas (Brock-Utne, 1985). Por um lado, esta abordagem alargada e interdisciplinar enriqueceu os estudos para a paz, mas, por outro, esta tendência resultou numa diluição do seu foco de análise. Acresce ainda que o factor distintivo dos estudos para a paz desde a sua fundação, uma abordagem baseada na investigação-acção, perdeu a sua dinâmica devido à incapacidade de traduzir eficazmente em acção os resultados da investigação para a paz.

\section{Conceitos de paz e violência}

Paul Lawler sintetiza as questões acima identificadas em três pontos, que iremos analisar neste artigo: "a ausência de um núcleo conceptual ou teórico substancial, a tendência para utilizar termos fundamentais de forma acrítica [...], e uma posição ambígua relativamente à violência directa" (2002: 9). Propomos a consolidação do núcleo teórico e conceptual dos estudos para a paz através não só da recuperação do valor central da paz, mas também do enquadramento da investigação e acção em culturas de pazes. Esta proposta baseia-se numa crítica à terminologia que a investigação para a paz definiu e que os actores no terreno têm vindo a adoptar. A posição ambígua relativamente à violência directa é aqui abordada com a introdução do conceito do continuum de pazes e violências e a nossa definição de paz. Esta análise pretende, deste modo, contribuir para uma melhor compreensão da relação entre investigação e acção defendida pelos estudos para a paz.

Os estudos para a paz têm "um núcleo conceptual [e] teórico substancial" (Lawler, 2002: 9), que é o valor da paz. No entanto, o alargamento da área disciplinar levou a uma diluição e segmentação do conceito. Paz é um conceito complexo e qualquer tentativa de melhor o definir será sempre alvo de críticas. Ainda assim, constitui um conceito central para os estudos nesta área, moldando a nossa visão relativamente aos objectivos, instrumentos e políticas a adoptar. Consequentemente, paz é aqui entendida como um processo holístico que implica a existência de condições básicas estruturais, incluindo a ausência de violência física e psicológica organizada, a satisfação das necessidades básicas humanas e, no plano institucional, estruturas representativas e de partilha proporcional do poder e a promoção e protecção dos direitos humanos. ${ }^{1}$ Em certa medida, esta definição de paz

\footnotetext{
${ }^{1}$ Este enquadramento conceptual também tem sido utilizado por outros autores, como Håkan Wiberg: "Desde a década de sessenta, propuseram-se valores diversos para ir além da ausência de violência física; os principais candidatos, hoje em dia, parecem ser os seguintes: 1) a equidade e bem-estar (isto é, a ausência de violência estrutural); 2) a liberdade (ausência de opressão); 3) a identidade (ausência de alienação ou de violência cultural).” (2005: 28).
} 
coincide com as pazes positiva e negativa de Galtung (1969); no entanto, pressupõe-se aqui que estas não devem ser, ainda que por razões metodológicas, separadas.

Este entendimento holístico de paz não é estático, uma vez que está inserido em culturas de pazes. Como definido pelas Nações Unidas

Cultura da Paz é um conjunto de valores, atitudes, formas de comportamento e modos de vida que rejeitam a violência e a previnem ao enfrentar as suas causas mais profundas para resolver problemas através do diálogo e da negociação entre indivíduos, grupos e nações (Nações Unidas, 1998a; 1998b).

Celia Cook-Huffman identifica esta transformação como o "desafio de integrar a análise estrutural na resolução de conflitos e de desenvolver práticas que levem a que as culturas de violência possam transformar-se em culturas de paz" (2002: 46). Esta análise decorre do trabalho desenvolvido por John Paul Lederach (2003), que considera que a transformação do conflito é um elemento central neste processo. ${ }^{2}$

Culturas de pazes, como as entendemos, diferenciam-se da definição das NU no sentido em que a abordagem que esta faz da resolução de problemas através do diálogo e da negociação não atende às condições estruturais subjacentes ao que define como 'cultura da paz'. Além do mais, as NU definem 'cultura da paz' como um conjunto de valores, atitudes e formas de comportamento. Contudo, podem existir diferentes conjuntos de valores, atitudes e formas de comportamento enraizados em passados históricos distintos, afinidades culturais, crenças religiosas e interacções sociais, que podem contribuir para dinâmicas de paz. Quanto ao conceito de paz em si, o seu entendimento holístico não implica apenas uma leitura. Isto significa que as diferentes componentes da paz podem combinar-se com diferentes intensidades criando diferentes pazes. Desde que estas componentes existam, existem também condições para a paz, sem implicarem um modelo único da mesma. Este entendimento não deve, no entanto, ser definido por oposição ao conflito, mas antes em relação à violência.

Entendemos que o conflito existe em todas as sociedades, tal como a paz e a violência. Contudo, este entendimento não constitui uma defesa da abordagem realista-hobbesiana ao conflito, no sentido de que a natureza humana é por definição violenta. Ou, para os mesmos efeitos, pacífica. No nosso entendimento, os conflitos não podem ser resolvidos no sentido de

\footnotetext{
${ }^{2}$ Este conceito de transformação é mais desenvolvido nos contextos de investigação em que a ‘cultura da paz' (Pureza, 2001) e a 'paz sustentável' (Reychler, 2001) são discutidas.
} 
serem eliminados. O que pode ser mitigado, e eventualmente eliminado na sociedade, é a violência, ou seja, a escolha da violência por oposição à paz quando abordamos os conflitos. Esta é uma escolha individual, apesar de influenciada por factores societais. Isto significa que os indivíduos podem escolher entre formas violentas ou pacíficas de gerir os seus conflitos. Mas mesmo em sociedades onde a escolha da violência é minimizada, os indivíduos não perdem a sua capacidade ou vontade de fazer uso da violência. Do mesmo modo, em sociedades onde a violência é uma escolha constante, os indivíduos não perdem a sua capacidade ou vontade de escolher a paz.

A dicotomia entre paz e guerra/violência é, deste modo, demasiado simplista. Para melhor entendermos as dinâmicas pacíficas e violentas de situações conflituais, parece-nos acertado adoptar o conceito de 'continuum de pazes e violências', de acordo com o qual as opções violentas são escolhidas com diferentes intensidades, mesmo em contextos de paz formal. Esta dicotomia baseia-se no pressuposto de que a violência, tal como a paz, é uma escolha. Como resultado, a escolha de meios pacíficos ou violentos reflecte as condições estruturais básicas acima mencionadas. Quando estas estão reunidas, há, claramente, uma maior tendência para recorrer a meios pacíficos de modo a responder aos conflitos. Além do mais, o conceito de paz está inserido num quadro normativo, onde a paz é o valor central que guia a teoria e a acção. Actuamos pela paz e não apenas para mitigar ou gerir a violência.

\section{A narrativa do conflito: uma crítica}

A proposta de acção dos estudos para a paz tem seguido a narrativa tradicional orientada para o conflito: prevenção de conflito $\rightarrow$ gestão de conflito $\rightarrow$ resolução de conflito $\rightarrow$ reconstrução pós-conflito. Esta narrativa é restritiva e falaciosa. Primeiro, os conflitos, como explicado acima, não podem ser prevenidos nem resolvidos, apenas geridos. Segundo, o que 'conflito' realmente significa nesta narrativa é 'violência'. A violência pode ser prevenida, gerida e resolvida no sentido de ser minimizada ou eventualmente eliminada, enquanto o conflito é intrínseco à vida em sociedade. Assim, esta narrativa reflecte o pressuposto tradicional de que o conflito e a violência são conceitos análogos, o que tem resultado numa distorção das premissas que sublinham a acção. Esta narrativa confina e direcciona estratégias, instrumentos e actores para o conflito. Para os estudos para a paz, o conflito é, obviamente, o problema, mas se o quadro de acção está confinado e enraizado no conflito, os resultados dificilmente podem ser enquadrados fora da narrativa orientada para o conflito e dessa forma darem resposta ao tema da violência. 
Além do mais, esta narrativa orientada para o conflito segue uma abordagem sequencial para a paz, no âmbito da qual primeiro a violência é gerida ou mitigada e só depois as condições estruturais para a paz são abordadas. Isto impede que o quadro holístico da paz seja implementado de forma adequada. De acordo com esta narrativa, quando a prevenção falha e se assiste a um aumento da violência, a preocupação primeira é de contenção ou término da mesma ('gestão de conflito'), geralmente através de um acordo de cessar-fogo, de modo a criar as condições favoráveis para a negociação de um acordo de paz ('resolução de conflito'). Quando as condições mínimas de segurança estão reunidas, os esforços de reconstrução pós-conflito são iniciados, envolvendo os actores e dinâmicas de reconstrução, e finalmente, respondendo às condições estruturais para a paz. Esta sequência não se encaixa, contudo, num conceito holístico de paz. Apesar de compreendermos que condições mínimas de segurança têm de estar asseguradas para que os aspectos mais estruturais possam ser garantidos, esta sequência lógica não permite que as conexões inerentes entre as diferentes fases sejam tidas em conta. E, no entanto, estas interligações são cruciais para envolver os diferentes actores e ligar as diferentes dinâmicas ao longo do processo, no sentido de uma paz duradoura e sustentável.

Os conceitos e terminologia avançados pelos estudos para a paz foram adoptados no sistema internacional, enquadrando as estratégias de intervenção. Deve ser relembrado que os estudos para a paz se autodefinem como uma área de investigação-acção, o que é claro nos documentos, mandatos e estratégias das NU, onde os "elementos de apoio à paz, [são] eles mesmos em parte derivados da terminologia da investigação para a paz" (Rogers e Ramsbotham, 1999: 750). O melhor exemplo desta ligação é a nova terminologia e abordagem dinâmica reflectidas na Agenda para a Paz.

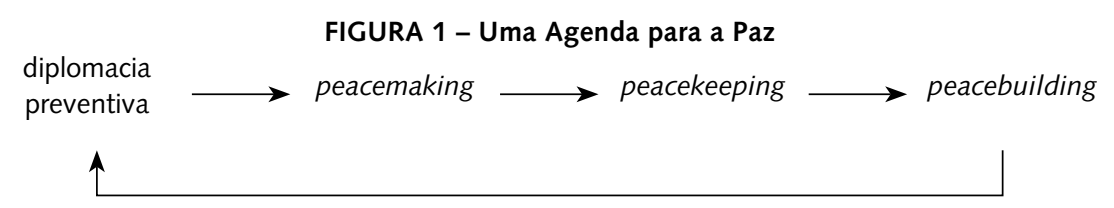

Fonte: Adaptado de Boutros-Ghali, 1992.

A estrutura avançada no documento Agenda para a Paz não perdeu a sua linearidade, mantendo um registo sequencial das estratégias de intervenção. É verdade que a terminologia reflecte uma abordagem centrada na paz, demarcando-se da narrativa orientada para o conflito. Contudo, 
esta demarcação não é suficiente para despoletar uma mudança fundamental na natureza das intervenções que lhe estão associadas, as quais permanecem focadas no conflito, isto é, na violência. Além do mais, a alteração da terminologia não foi acompanhada por uma mudança dos instrumentos adoptados, que permanecem orientados militarmente. A manutenção da paz não é só um bom exemplo desta demarcação, mas também das limitações que a mesma implica.

\section{As missões de paz como ilustração da desconexão investigação-acção}

O peacekeeping é talvez o melhor exemplo da mencionada desconexão entre investigação e acção. E, contudo, é também um bom exemplo de uma tentativa clara de a ultrapassar. A Carta das NU não prevê missões de paz, apesar de conter elementos e princípios que reflectem o espírito dentro do qual o peacekeeping e o peacebuilding são prosseguidos. Assim, a lógica acordada para enquadrar as missões de paz encontrava-se entre o Capítulo VI (resolução pacífica de disputas) e o Capítulo VII (medidas de imposição da paz quando esta está ameaçada ou é violada, ou frente a actos de agressão). Alguns chamam-lhe 'Capítulo VI 1/2’: soldados enviados para o terreno com mandato restrito quanto ao uso da força. Estas primeiras missões observavam o cumprimento das condições definidas nos acordos de paz. O seu principal objectivo era assegurar que a violência física não fosse perpetrada por nenhum dos grupos beligerantes (a paz negativa de Galtung, onde a violência directa está ausente). Contudo, dois problemas principais resultaram da definição destas missões com estes mandatos. Primeiro, os grupos beligerantes não eram facilmente identificados, o que tornava mais difícil para a missão controlar quem respeitava e quem violava as condições de paz acordadas. Lembre-se que os soldados que integram estas missões estão treinados para defender e lutar contra um oponente identificado, o que exacerba a situação. Segundo, apesar de algum tipo de paz ser acordado antes de os peacekeepers serem enviados para o terreno, um problema recorrente é que, mesmo em contextos de paz formal, a violência pode persistir.

O continuum das pazes e das violências explica como, em contextos de paz formal, podemos encontrar actos de agressão ao estilo de guerra. Estes soldados supostamente não se envolvem em luta, a menos que atacados e em condições muito restritivas. Consequentemente, actos de agressão perpetrados entre grupos beligerantes, ou quaisquer outros grupos, não representam objecto de intervenção dos soldados da paz. O máximo que podem fazer é reportar que um ou vários grupos não estão a cumprir com o acordado. A desconexão entre investigação e acção é, assim, clara. Apesar de o 
objectivo ser restaurar e garantir a paz, os instrumentos e o pessoal não se adequam, uma vez que, por exemplo, o treino desse pessoal é dirigido para a violência. Além do mais, a dicotomia convencional guerra/violência e paz subverte os mandatos destes soldados. Em benefício da paz, eles não devem lutar e, devido à violência que ainda ocorre, não qualificada como guerra, falham no cumprimento dos seus mandatos e na protecção quer de civis, quer deles próprios. As causas de base para a violência persistem, sendo que, mesmo ficando aquém da guerra civil ou do conflito armado anterior à chegada da missão de paz, são socializadas, tornando-se menos visíveis. E, deste modo, a violência torna-se invisível para os soldados, uma vez que se transforma de uma ameaça à paz internacional num tema de criminalidade interna/transnacional.

As NU, em face destes desenvolvimentos e do facto de os estudos para a paz estarem a alargar o seu objecto de análise para abranger condições sociais, económicas e culturais, identificaram a necessidade de ajustar as suas missões de paz. E, com esse objectivo, nos anos oitenta e noventa, um novo tipo de missões de paz tomou forma. Sentiu-se a necessidade de adaptar os mandatos para incluírem mais do que a observação e manutenção da paz, nomeadamente, a segurança humana, a consolidação de confiança, acordos de partilha de poder, apoio eleitoral e desenvolvimento social e económico. Estas novas missões foram para além dos seus mandatos iniciais e envolveram soldados, polícia e pessoal civil. Até então, peacebuilding estava geralmente nas mãos de agências de apoio ao desenvolvimento, bi- e multilaterais, e de organizações não-governamentais. Estas esperariam até que no terreno estivessem reunidas condições de segurança para intervirem e só depois o peacebuilding seria iniciado, na chamada fase de 'reconstrução pós-conflito'. A incorporação destas preocupações nos mandatos das missões de paz reflecte o entendimento de que o peacebuilding tem de ser iniciado antes da contenção da violência.

Esta perspectiva reflecte também uma mudança significativa no conceito operacional de paz das NU: paz é mais do que o fim da violência. O objectivo destas intervenções torna-se a criação de uma 'cultura da paz', através da resposta a necessidades imediatas de segurança e urgência humanitária, bem como às causas da violência. Este é um elemento absolutamente inovador. As missões de paz tornam-se multidimensionais, envolvendo preocupações de segurança, institucionais, económicas e psicossociais. A dimensão de segurança segue os mandatos originais das missões de paz, garantindo-a através da ausência de violência. A dimensão institucional está relacionada com os regimes e sistemas políticos, de modo a enquadrar os esforços desenvolvidos e a criar um sistema pacífico de gestão dos conflitos. 
Geralmente, engloba o sistema judicial, partidos políticos, e governação multi-nível. A dimensão económica visa a criação de uma economia de mercado liberal favorável ao investimento e focada no crescimento económico e desenvolvimento. A integração de ex-combatentes é crucial nesta dimensão. Por fim, todos estes esforços são insuficientes a menos que o tema da reconciliação social seja abordado, incluindo as partes envolvidas - esta constitui a dimensão psicossocial.

De novo, há uma tentativa clara de responder à realidade tendo em atenção os resultados da investigação dos estudos para a paz. Mas dois problemas estruturais permanecem: instrumentos e pessoal. Apesar de incluírem um número mais elevado de civis, a maior parte dos peacekeepers são soldados, como acima referido, treinados para a guerra; e, rapidamente, os mandatos tornaram-se quase impossíveis de cumprir, dado que esta multidimensionalidade se tornou demasiado abrangente. O objectivo era garantir a paz através de meios pacíficos e enquadrar estas missões claramente no âmbito do Capítulo VI da Carta das NU, mas os soldados não são treinados com esse enfoque. Além do mais, apesar de o conceito de paz em sentido amplo ter sido socializado neste tipo de missões, o de continuum de pazes e violências não o foi. As intervenções dirigem-se às violências identificadas ao longo de um conflito armado, contudo, estas dinâmicas não são apenas erradicadas com a assinatura de um acordo de paz e o envio para o terreno de peacekeepers. As dinâmicas de violência persistem, muitas vezes tomando diferentes formas, em diferentes planos e com dimensões diferenciadas, tornando-se, por consequência, invisíveis aos peacekeepers, mas não perdendo o seu impacto violento na sociedade.

Desde o início do século XXI, as missões de paz sofreram ainda outro desenvolvimento, numa tentativa de responder à experiência cumulativa e à evolução conceptual da investigação. Se com as missões de paz multidimensionais a alteração se verificava em direcção ao Capítulo VI da Carta das NU, com este novo tipo de missões, o movimento inverteu-se na direcção do Capítulo VII. Parece que finalmente há intenção de conferir 'garras e dentes' a estas missões e o foco está agora centrado na segurança humana colectiva.

Esta alteração foi acompanhada por três factores, numa tentativa de fornecer consistência e coerência a estas preocupações. Primeiro, em 2000, o Relatório Brahimi permitiu a criação das condições para um sistema de peacekeeping em dois níveis: por um lado, missões de paz lideradas e coordenadas pelas NU e, por outro, missões autorizadas pelas NU, mas lideradas e coordenadas por um estado-membro, um grupo de estados ou uma 
organização internacional. A última visando o recurso à violência, se necessário, para o cumprimento da implementação operacional do mandato. Contudo, as propostas avançadas no Relatório Brahimi

representam uma abordagem de gestão ou de 'resolução de problemas' para melhorar as missões de paz que não responde ao fundamental das questões estruturais, procurando, ao invés, lidar com fontes particulares de dificuldades nas estruturas políticas contemporâneas. (Bellamy and Williams, 2004: 2)

O relatório incarna a visão de que há um acordo consensual sobre o que constitui uma crise, os elementos da solução e as estratégias mais apropriadas para a alcançar, deste modo perpetuando a ortodoxia tradicional. Assim, o valor central da paz permanece minimizado neste processo.

Em segundo lugar, a criação da Comissão de Peacebuilding (CSNU Res. $1645,2005)$ pelo Conselho de Segurança das Nações Unidas tinha como objectivo principal coordenar esforços de peacekeeping e peacebuilding, bem como constituir a ligação entre peacebuilding e a prevenção da violência. Contudo, apesar deste esforço, as causas de base da violência podem permanecer, com potencial para uma nova escalada, e novas causas podem surgir devido ao modelo de reconstrução promovido. É aqui que a importância das culturas de pazes deve ser sublinhada. Estas culturas de pazes terão de ser articuladas com os valores e tradições de cada sociedade para que possam florescer, um processo de criação e consolidação da paz que implica já uma natureza preventiva. De facto, a incorporação de culturas de pazes cria as condições para o uso de meios pacíficos na resposta aos conflitos, em vez de meios violentos. As causas dos conflitos não desaparecem, mas o processo de lidar com elas muda.

Em terceiro lugar, em 2008, as NU apresentaram um manual de princípios e linhas orientadoras para o envio de missões de paz para o terreno, agregando as naturezas multidimensional e multinível da sua implementação. Podemos ainda argumentar que um outro tipo de missões tem estado a tomar forma nas últimas décadas, com base em desenvolvimentos recentes, em particular em Timor Leste e no Kosovo, adicionando a esta multidimensionalidade e natureza multinível um elemento de governação mais explícito, traduzido nas administrações transitórias. Contudo, não é suficiente fechar o ciclo linear do conflito articulando 'reconstrução pós-confito' com prevenção da violência/promoção da paz. Defendemos que este processo deve ser levado mais além. Não deve ser entendido como um processo linear faseado, mas antes como uma rede complexa, onde os diferentes elementos se interligam e desenvolvem dentro das culturas de pazes. 


\section{Investigação e acção: novos caminhos conceptuais e operacionais para as missões de paz}

O quadro holístico de paz avançado implica a existência de áreas de intervenção correlacionadas, por oposição a fases sequenciais, uma vez que as pazes positivas e negativas estão intrinsecamente ligadas, como analisado em seguida. Além do mais, estas interacções estão enraizadas em culturas de pazes, onde as áreas de intervenção estão inter-relacionadas, criando o que designamos por peace web.

FIGURA 2 - Peace Web

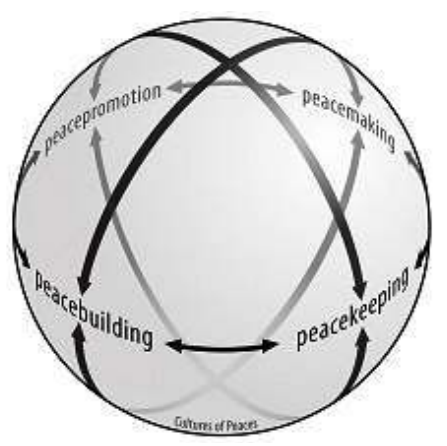

No seio da peace web, as relações entre os nós são bi-direccionais e não-lineares. Por outras palavras, cada nó é influenciado e influencia os outros. Para esta abordagem ter resultados pacíficos, estas dinâmicas devem incluir valores, atitudes e modos de acção pacíficos, como definidos pelas culturas de pazes. Isto aplica-se a cada nó, independentemente de onde ou quando a intervenção tem lugar.

A peace web reflecte estratégias de intervenção diferenciadas, que incorporam instrumentos distintos. Estes estão correlacionados e são aplicados com diferentes níveis de intensidade de acordo com a situação a que estão a responder. Isto significa que a promoção da paz, o peacemaking, o peacekeeping e o peacebuilding não são áreas de intervenção sequenciais, mas correlacionadas. De facto, estas áreas não são fechadas ou excludentes, apoiam-se mutuamente de forma articulada e flexível para o objectivo comum da paz. A promoção da paz implica, assim, uma estratégia de consolidação de confiança, que visa criar condições para uma escolha de meios não violentos como resposta ao conflito. Esta estratégia inclui instrumentos como a criação de linhas de comunicação, de cenários de partilha de poder, de um ambiente propício à discussão de temas relacionados com ressentimentos e/ou justiça. Estes instrumentos devem estar sempre presentes, 
mesmo que num contexto de paz formal. Como foi defendido, os contextos de paz formal ainda incluem meios violentos num continuum de pazes e violências, que não deve ser ignorado.

O peacemaking é uma área de intervenção essencialmente pertinente como resposta à violência armada organizada e a contextos formais de paz violentos. Inclui não só os instrumentos tradicionais de negociação, mediação e second-track com vista à obtenção de um cessar-fogo ou acordos de paz, mas visa também a criação de linhas de comunicação directas, arranjos representativos de partilha de poder e, em geral, o estabelecimento de medidas de consolidação de confiança entre as partes. O peacekeeping, como área de intervenção, centra-se na manutenção da paz, respondendo à violência armada organizada e a contextos de paz formal violentos. Isto implica o envio de peacekeepers, entendidos aqui como forças civis e de segurança (polícia), para além de soldados, com um mandato multidimensional de manutenção da paz. Simultaneamente, é visado o recurso a instrumentos mais institucionais, como o estabelecimento de um estado de direito, sistema judicial, estruturas representativas e de partilha proporcional de poder, promoção e protecção dos direitos humanos, e criação ou (re)capacitação das forças internas de segurança por forma a permitir o (re)estabelecimento do monopólio do uso legítimo da força pelo Estado.

$\mathrm{O}$ peacebuilding procura consolidar e promover a paz. Com base nos instrumentos institucionais do peacekeeping, o peacebuilding implica ainda reconstrução económica, medidas de facilitação da reconciliação social, integração de ex-combatentes, entre outros. Estas áreas de intervenção contribuem e são sustentadas por culturas de pazes, que advogam valores, atitudes, comportamentos e modos de vida pacíficos. Ao enquadrar estas áreas de intervenção na peace web, o resultado é uma abordagem dinâmica e integrada para a paz, a qual é interligada, em vez de sequencial e faseada, permitindo uma abordagem holística que faz com que a agenda investigação-acção seja um objectivo alcançável.

Esta proposta conceptual requer uma revisão estrutural no âmbito operacional. Apesar de defendermos que os instrumentos existentes têm potencial para responder a questões de paz e violência, estes mesmos instrumentos encontram-se baseados em conceitos cuja operacionalização limita o seu sucesso. Desta forma, não apresentamos uma proposta de criação de novos instrumentos, antes defendemos uma articulação e implementação diferenciadas dos processos actuais, com base numa transformação operacional dos mesmos. Primeiro, relativamente ao timing, as intervenções não devem ser delineadas de forma sequencial dependendo do seu foco, mas antes de forma correlacionada como apresentado na peace web. Segundo, esta trans- 
formação requer que as intervenções incluam pessoal militar, de segurança pública (polícias) e civil, num esforço conjunto e coordenado. Isto significa que as estratégias, os planos de acção e os processos de tomada de decisão têm de ser conjuntos por forma a melhor responder à complexidade das realidades no terreno. Esta forma de operacionalizar os instrumentos existentes corresponde às múltiplas relações identificadas na peace web. Adicionalmente, estas intervenções devem ser explícita e especificamente enquadradas em conjuntos de valores, comportamentos e modos de vida que rejeitem a violência e promovam a paz. Apenas quando a investigação e a acção partirem da mesma ontologia e actuarem com base na mesma ontologia é que as culturas das pazes terão condições para se enraizar.

\section{Conclusão}

Os resultados da investigação dos estudos para a paz transitaram para o discurso político e para os instrumentos das missões de paz. No entanto, os resultados têm ficado aquém das expectativas. Por um lado, o alargamento da agenda dos estudos para a paz, a par da desconexão entre os resultados operacionais e as propostas de investigação, fragilizou os estudos para a paz como área de estudo. Por outro lado, estas mesmas dinâmicas permitiram a legitimação dos instrumentos operacionais de uma forma perversa. Ao incorporarem a terminologia dos estudos para a paz e os resultados da investigação para a paz, os actores no terreno e os decisores políticos legitimaram o uso de instrumentos tradicionais 'equipados' com esta nova linguagem e enquadramento. Este processo levou a resultados frustrantes e mal sucedidos no que diz respeito à operacionalização da relação investigação-acção nos estudos para a paz. Defendemos que esta frustração não pode ser resolvida através de uma abordagem de 'resolução de problemas' ou através de um mero ajustamento dos mecanismos existentes. A peace web faculta o quadro conceptual para uma transformação da abordagem operacional à paz, a qual deve reflectir o valor fundamental da paz enraizada em culturas das pazes e responder às questões subjacentes ao continuum das pazes e das violências.

O valor fundamental da paz não pode ser promovido através de uma abordagem de 'resolução de problemas', uma vez que a solução para o 'problema' não é necessariamente equivalente à paz. Paz é um processo holístico que implica a ausência de violência física e psicológica organizada, a satisfação de necessidades básicas humanas e, no plano institucional, estruturas representativas e de partilha proporcional de poder, para além da promoção e protecção dos direitos humanos. A operacionalização deste conceito implica que as motivações subjacentes à participação de diferentes 
estados nas missões de paz proporcionem uma indicação dos valores inerentes às mesmas.

As culturas das pazes são essenciais para enraizar os esforços destas missões nas dinâmicas locais. Isto requer um conhecimento e compreensão dos valores, atitudes, comportamentos e modos de vida locais. As missões de paz precisam de se enraizar nestas dinâmicas de forma a melhor responderem aos conflitos existentes e a contribuírem para a transformação dos mesmos através de meios pacíficos. Isto deve ser conseguido através de um processo constante e auto-sustentado, tendo em atenção o continuum de pazes e violências.

A peace web, ao ultrapassar a abordagem sequencial e faseada da 'narrativa do conflito', aborda este continuum de pazes e violências. Os mandatos e as estratégias de intervenção das missões de paz devem ser transformados de forma a darem resposta às diferentes combinações de paz e violência existentes nas realidades locais. Todos os elementos da peace web - promoção da paz, peacemaking, peacekeeping e peacebuilding - devem estar representados em cada missão, com diferentes intensidades, respondendo a diferentes pazes e violências locais. Isto significa que as missões de paz têm de ser flexíveis o suficiente para responder a variações deste continuum. Um desafio que requer investigação futura.

\section{Referências bibliográficas}

Bellamy, Alex; Williams, Paul (2004), "Introduction: Thinking Anew about Peace Operations”, International Peacekeeping, 11(1), 1-15.

Booth, Ken (2001), "New Wars for Old", Civil Wars 4(2), 163-170.

Boulding, Elise (2000), Cultures of Peace: The Hidden Side of History. Syracuse: Syracuse UP. Boutros-Ghali, Boutros (1992), An Agenda for Peace: Preventive Diplomacy, Peacemaking and Peace-keeping. Report of the Secretary-General pursuant to the statement adopted by the Summit Meeting of the Security Council on 31 January 1992 (A/47/277 -S/24111, 17 June 1992). Disponível em http://www.un.org/docs/SG/agpeace.html [consultado em 18/01/2008].

Brock-Utne, Birgit (1985), Educating for Peace: A Feminist Perspective. New York: Teachers College Press.

Buzan, Barry et al. (1997), Security: A New Framework for Analysis. Boulder: Lynne Rienner Publishers.

Cook-Huffman, Celia (2002), "Paths for Peace Studies", Peace Review, 14(1), 41-47.

CSNU (2005), Resolution 1645. United Nations Security Council Resolutions. Disponível em http://daccessdds.un.org/doc/UNDOC/GEN/N05/654/17/PDF/N0565417. pdf?OpenElement [consultado em 15/12/2007]. 
Duffield, Mark (2001), Global Governance and the New Wars: The Merging of Development and Security. London: Zed Books.

Dunn, David J. (2005), The First Fifty Years of Peace Research - A Survey and Interpretation. Hampshire and Burlington: Ashgate.

Galtung, Johan (1969), "Violence, Peace and Peace Research”, Journal of Peace Research, 6(3), 167-191.

Galtung, Johan (1996) Peace by Peaceful Means: Peace and Conflict, Development and Civilization. London: PRIO / Sage Publications.

Hobbes, Thomas (1651), Leviathan. Disponível em http://oregonstate.edu/instruct/ phl302/texts/hobbes/leviathan-contents.html [consultado em 10/03/2008].

Kaldor, Mary (1999), New and Old Wars: Organised Violence in a Global Era. Cambridge/Stanford: Polity Press/Stanford UP.

Lawler, Peter (2002), "Peace Research, War, and the Problem of Focus", Peace Review, 14(1), 7-14.

Lederach, John Paul (2003), The Little Book of Conflict Transformation. Intercourse: Good Books.

Martínez Guzmán, Vicent (2005), "Filosofia e investigação para a paz”, Revista Crítica de Ciências Sociais, 71, 43-62.

Mason, Gregory (2002), "PeaceStudies in the NextHalf-Century”, PeaceReview, 14(1), 15-19.

Moura, Tatiana (2005), "Novíssimas guerras, novíssimas pazes. Desafios conceptuais e políticos.”, Revista Crítica de Ciências Sociais, 71, 77-96.

Nações Unidas (1998a), Resolution A/RES/52/13: Culture of Peace. United Nations Resolutions. Disponível em http://www3.unesco.org/iycp/uk/uk_sum_cp.htm [consultado em 24/02/2008].

Nações Unidas (1998b), Resolution A/RES/53/243: Declaration and Programme of Action on a Culture of Peace. United Nations Resolutions. Disponível em http://www3. unesco.org/iycp/uk/uk_sum_cp.htm [consultado em 24/02/2008].

Pureza, José Manuel (org.) (2001), Para uma cultura da paz. Coimbra: Quarteto.

Pureza, José Manuel; Cravo, Teresa (2005), "Margem crítica e legitimação nos estudos para a paz”, Revista Crítica de Ciências Sociais, 71, 5-19.

Reychler, Luc (2001), "From Conflict to Sustainable Peacebuilding: Concepts and Analytical Tools”, in Luc Reychler; Thania Paffenholz, Peacebuilding: A Field Guide. London: Lynne Rienner.

Rogers, Paul; Ramsbotham, Oliver (1999), “Then and Now: Peace Research - Past and Future", Political Studies, 47, 740-754.

Terriff, Terry et al. (1999), Security Studies Today. Cambridge: Polity Press.

Tromp, Hylke (1981), "Introduction: Changing Perspectives in Peace Research", in UNESCO Yearbook of Peace and Conflict Studies 1980. Westport, CN: Greenwood Press. Wiberg, Håkan (2005), "Investigação para a paz: passado, presente e futuro”, Revista Crítica de Ciências Sociais, 71, 21-42. 